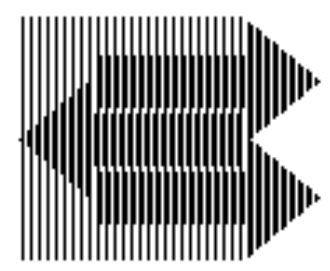

MIT EL 01-001 WP

Energy Laboratory

Massachusetts Institute of Technology

\title{
A reliability insurance scheme for the electricity distribution grid
}

\author{
January 2001
}




\title{
A reliability insurance scheme for the electricity distribution grid
}

Elena Fumagalli, Jason Black, Marija llic, Ingo Vogelsang

\section{Energy Laboratory Publication \# MIT EL 01-001 WP}

\author{
Energy Laboratory \\ Massachusetts Institute of Technology \\ Cambridge, Massachusetts 02139-4307
}

January 2001 


\title{
A reliability insurance scheme for the electricity distribution grid
}

\author{
E-Lab Working Paper
}

\author{
Elena Fumagalli^, Jason Black*, Marija Ilic*, Ingo Vogelsang** \\ *MIT E nergy L aboratory, Cambridge M A \\ **Boston U niversity, Boston, MA \\ ^U niversita' degii Studi di Padova, Italy and M IT E-L ab (visiting)
}

\begin{abstract}
In this paper, we examine the interplay of regulatory structures and the use of technology on the electricity distribution grid. The emphasis is on the incentives provided by regulation for efficient investment in capital and technology. Several regulatory structures are examined to determine their relative affects on investments in technologies, especially new technologies that can improve efficiency. These affects are measured in terms of the effects on the costs of delivery and the reliability seen by the consumers. Both Rate of Return and Performance Based Regulation with penalties for reliability failures are assessed for their relative strengths and weaknesses. As a result of this analysis, we find a need for a regulatory structure that provides incentives for both cost efficiency and quality of service. As a result, we propose an insurance scheme for reliability service under performance based regulation for delivery service. Implementing insurance for eliability will allow consumers to provide economic signals to the distribution provider. These signals enable the distribution provider to make economically efficient investment decisions for both capital and technology. The insurance also allocates the risk of outages to the distribution provider (who has control of the system), rather than to the consumer (as it is now). The implementation of reliability insurance also provides a relatively simple method for unbundling the delivery and reliability services and enables consumers to receive differentiated reliability service based upon their value for this service. This paper elaborates upon the proposed reliability insurance scheme and shows how it improves overall social welfare
\end{abstract}

\section{Introduction and motivation}

A systematic approach to the optimal engineering design of a distribution system, with well defined technical and economic performance criteria, cannot be completed without considering the 
regulatory framework within which the distribution market functions. The regulatory structure, on one side, and the decisions made by the distribution utility, in terms of use of technology, investment choices, and reliability provision, on the other, are strongly correlated. The regulatory framework, in fact, provides strong incentives for the utility to behave in certain ways or to make different decisions. In order to gain some insights about the interplay of regulatory structure and utility's behavior, we develop here a scenario analysis of a simplified distribution grid and analyze the utility most likely behavior under various regulatory structures. A study of two of the currently most used regulatory setups revealed some well-known weaknesses in the incentives they give to the distribution utility to work efficiently. Moreover, they demonstrated that reliability is not optimally provided; in particular, is not correlated to the value of this service for the consumers. In order to capture the consumer value of delivery service and to provide good signals for investment and operation, we propose, first, a reliability penalty scheme and, secondly, we argue that an insurance scheme would be actually better suited to eliminate some of the above-mentioned problems associated with the current pricing structure and will provide important signal from the consumers' side.

Before proceeding in the analysis various regulatory schemes, it is important to define clearly the market structure and the distribution utility structure (the services it provides, its position in the market... ). This is the argument of the following paragraph.

\section{Our model and framework}

We consider the distribution utility as an operator and owner of the distribution grid, which is not involved in any generation activity, or in energy retailing. In other words, the distribution utility is responsible for investment in distribution assets and is the monopoly provider of energy delivery service. It also provides reliability, voltage support and other ancillary services. In this paper, we focus solely on delivery and reliability service.

For the case of delivery and reliability service only, a good regulatory scheme gives the distribution provider (DP) good incentives to efficiently manage delivery while at the same time meeting consumers' reliability requirements. Such a regulatory scheme can be designed so that the D P's short term decisions concerning the use of existing assets and long term investment decisions are driven by consumers' values for delivery and reliability services.

We define reliability as the total duration of all outages times the amount of load not served, that is, the total amount of energy not delivered to consumers. This measure is appropriate because from the consumers' point of view the cause of a deficit in the energy provided, whether it is due to line outages, congestion, generator failure, lack of voltage support, etc., is not relevant. The energy not served, therefore, is an appropriate index, also easily verifiable by consumers themselves. The value of the energy not delivered can be used as an accurate and quantifiable measure of consumer preferences for reliability service.

\subsection{Assumptions}

A simple radial distribution grid with inelastic demand and static loads is used as an example. The actual grid used for simulation is represented in Figure1. Some possible improvements on the grid are also illustrated: the rectangles at the consumers' sites represent the introduction of technical equipment for communication and control of the loads, such as remotely controlled switches or intelligent meters (AMRs). Improvements on the topology of the grid are also considered: the normally open switch permits to operate the grid normally as radial and to close the loop in case of a fault to restore a number of consumers. In our example, the change in topology requires also to invest in the extra line. 


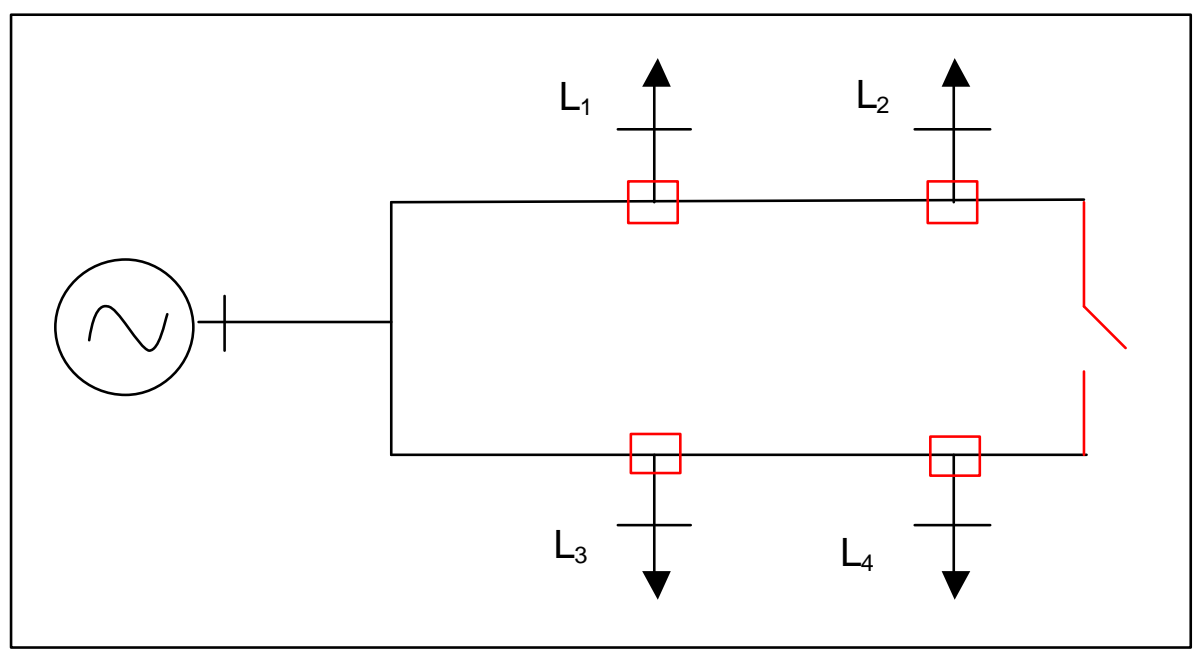

Figurel Example of a simple radial distribution grid

As a general setup, the DP operates under a monopoly scheme for the distribution network and its revenues come only from delivery services. Along with the delivery service, the DP provides a standard reliability that can be considered either as a product embedded in the delivery service or can be unbundled and offered as a separate service. O ur analysis regards mainly two regulatory schemes, rate of return regulation and a form of performance-based regulation, price caps. In Table 1 below there is a synthesis of the three case addresses. In the first two a penalty scheme is considered and for the third one an insurance scheme is developed.

\section{Table 1 Scenarios}

\begin{tabular}{|l|l|l|l|l|l|}
\hline Regulatory structure & Senvices & Customer choice & Effort on 0\&M & Topology & Use of IT \\
\hline ROR + Penalties & $\begin{array}{l}\text { D elivery } \\
\text { Reliability }\end{array}$ & No & Normal & Radial/loop & No \\
\hline PCR + Penalties & $\begin{array}{l}\text { D elivery } \\
\text { Reliability }\end{array}$ & No & Normal/ Low & Radial/ loop & No \\
\hline PCR + Insurance & $\begin{array}{l}\text { Delivery } \\
\text { Reliability }\end{array}$ & Yes: insurance & Normal & Radial & Yes \\
\hline
\end{tabular}

A penalty scheme, in this form or in another, has been used by regulators already, whereas, the development of an insurance scheme for the distribution grid has never been proposed. This represent the most innovative part of the paper, and provides extremely interesting results.

\section{Rate of return regulation with a penalty scheme for reliability}

Rate-of-return (ROR) regulation has been used widely in the electricity market, and represents the most common regulatory scheme for distribution companies. It is a form of cost-plus regulation and can be characterized as follows.

The revenues requirements for the D P are derived from operating costs plus capital costs times a rate of return on capital, with the latter determining the company's profits. ROR is set a level that permits the firm to raise capital for investment and for the shareholder to make profits. RO R rate cases are based on historical costs data, i.e. the company provides its operating costs, the capital employed, and the costs of capital and the regulator audit these data and determines a fair rate of return on capital employed. The utility normally can only persuade its regulator to change (raise) its prices and revenues if it can show that its average costs have changed. 
Since the publication of the original paper by Averch and Johnson (A-J), ROR regulation has been criticized for not providing incentives to minimize costs or improve efficiency. The A-J model examines how a regulated firm chooses its inputs when the regulator has no control over its choice and the firm is permitted a rate of return exceeding the cost of capital. The point is that capital investment expands the rate base on which the firm is allowed an excess rate of return and this induces the firm to select capital-labor ratios in favor of capital. The A-J model generated strong implications. For instance, it implies that regulated firms do not implement policies to reduce the need for capacity expansion (for example peak load pricing), and that, it favors high standards of reliability on the grid (as a result of over investment in capital).

Of course, it can also be argued that ROR served a very useful role during the high-growth periods of the electric industry by securing rapid investment in key infrastructure. Clearly, the situation has changed in opening some sectors of the industry to competition and especially in terms of the technology available. Regulation itself should adequately respond to those changes ([7], [5], [1]).

In the first scenario examined in this paper, the DP is a regulated monopoly subject to ROR regulation and offers both delivery and reliability service. The two services are bundled into a single tariff paid by the grid users. The utility faces a penalty scheme for failures to deliver power [credits to Anuradha]. The tariff $(\mathrm{P})$ is assumed to be a linear tariff and the penalties (Pen) are assumed to be a given price per MWh not delivered. In addition, the total quantity of energy to be delivered during the season is assumed to be known at the beginning of the time period $\left(\mathrm{Q}_{\mathrm{tot}}\right)$. Under this scheme the firm's objective function for a given season (2160 hours) becomes:

$$
\max \Pi=P Q_{\text {tot }}-C=C_{\text {capital }} \cdot(s-r)-P e n
$$

where:

$\begin{array}{ll}\Pi & \text { is the firm's profit } \\ P & \text { is the linear electricity tariff per kWh, including delivery and reliability; } \\ Q_{\text {tot }} & \text { is the total amount of energy scheduled to be delivered by DP during a given season; } \\ \text { C } & \text { are total costs (fixed and variable), including penalties; } \\ C_{\text {capital }} & \text { are the costs of capital inputs; } \\ \text { S } & \text { cost of capital; } \\ \text { r } & \text { is the allowed rate of return, fixed by the regulator. }\end{array}$

Assuming that the penalty function is linear and that the cost of capital inputs is given by the following 4 elements: cost of new distribution lines $\left(\mathbb{C}_{1}\right)$; cost of lines to change the topology of the grid from a radial to a looped configuration $\left(\mathrm{C}_{\mathrm{K}}\right)$; cost of conventional equipment used on the lines $\left(\mathrm{C}_{e}\right)$; and cost of control equipment that improves reliability $\left(\mathrm{C}_{\beta}\right)$; equation (1) becomes:

$$
\max _{\beta, K, \text { Pen }} \Pi=(s-r) \cdot\left(C_{l}+C_{K}+C_{e}+C_{\beta}\right)-\rho Q_{u n}
$$

where:

$\rho \quad$ is the penalty;

$Q_{\text {un }} \quad$ is the amount of energy not transferred by D P during the season.

Given this objective function, we ran a simulation on the simple distribution grid in Figure 1, choosing illustrative numbers as input data. The goal was to verify what type of decisions in terms of investment and in reliability level offered to consumers is more profitable for the DP under in this regulato ry framework. In Table 2 we see the basic input data. 
Table 2 Basic Input data for R0R scenario

\begin{tabular}{|l|l|r|}
\hline Price (delivery only) (\$/MWh) & $\mathrm{P}_{\text {reg }}$ & 3.87 \\
\hline Time Period (hours) & $\mathrm{T}_{\text {tot }}$ & 2160 \\
\hline Average Demand (MW) & $\mathrm{Q}_{\text {tot }}$ & 10 \\
\hline Cost of Equipment (\$) & $\mathrm{C}_{\mathrm{e}}$ & 20,000 \\
\hline Cost of Lines (\$) & $\mathrm{C}_{\mathrm{l}}$ & 15,000 \\
\hline Cost of Operations (\$) & $\mathrm{C}_{\mathrm{o}}$ & 45,000 \\
\hline Rate of Return & $\mathrm{R}$ & 0.1 \\
\hline Outages (/period) & $\mathrm{Int}$ & 1.00 \\
\hline Outage Duration (hours) & $\mathrm{D}_{\text {out }}$ & 2 \\
\hline Cost of Technology Investment $(\$)$ & $\mathrm{C}_{\mathrm{b}}$ & $4,000.00$ \\
\hline Cost of Capital Investment $(\$)$ & $\mathrm{C}_{\mathrm{k}}$ & $5,000.00$ \\
\hline
\end{tabular}

For simplicity, we consider reliability as a measure of continuity of service. Therefore, reliability is measured by the product of the number of outages in a season and the average duration of the outages, in hours. Two investment options are available for the DP: Investing in control Technology or modifying the topology of the grid. The effect on reliability of the different investments is modeled as a parameter that modifies the duration of outages. Putting smart switches or AMR equipment at each load (Tech) reduces the time to find and precisely locate a fault on the network and, therefore, the duration of the curtailment for the consumers. Changing the topology of the grid (Capital) to a loop with a manual or automatic switch reduces considerably the average time of restoration. The restoration time is significantly reduced for certain consumers, depending on the location of the fault. Investment in both of the above schemes further reduces the average duration of outages. The numbers for the duration of outages are given in Table 3.

Table 3 E ffect of investments on Reliability

\begin{tabular}{|l|l|r|}
\hline Outage with no investments & $D_{\text {out }}$ & 2 \\
\hline Outage with Tech (hours) & $D_{\text {out }}$ & 1 \\
\hline Outage with Capital (hours) & Dout $_{1}$ & 0.5 \\
\hline Outage with Tech and Capital (hours) & D out $_{1}$ & 0.1 \\
\hline
\end{tabular}

When consumers experience a loss of load, it is assumed that they do not pay for the energy not delivered and, in addition, that the D P pays them back an amount proportional to $\mathrm{Qun}_{\text {un }}$ according to a penalty, $\rho$, set by he regulator. In the simulation we let the penalties vary between 0 and 100 (\$/ MWh) to see at what point the penalties become significant enough to modify the D P's optimal investment decisions. The results of the simulation are given in Table 4.

Table 4 ROR simulation results

\begin{tabular}{|l|c|c|c|c|c|}
\hline Penalties & $\rho=0$ & $\rho=1$ & $\rho=5$ & $\rho=50$ & $\rho=100$ \\
\hline Investment decisions & \multicolumn{5}{|c|}{ Profit } \\
\hline Nothing (base case) & $\$ 3,500.00$ & $\$ 3,480.00$ & $\$ 3,400.00$ & $\$ 2,500.00$ & $\$ 1,500.00$ \\
\hline Tech & $\$ 3,900.00$ & $\$ 3,880.00$ & $\$ 3,800.00$ & $\$ 2,900.00$ & $\$ 1,900.00$ \\
\hline Capital & $\$ 4,000.00$ & $\$ 3,980.00$ & $\$ 3,900.00$ & $\$ 3,000.00$ & $\$ 2,000.00$ \\
\hline Both & $\$ 4,400.00$ & $\$ 4,380.00$ & $\$ 4,300.00$ & $\$ 3,400.00$ & $\$ 2,400.00$ \\
\hline
\end{tabular}




\begin{tabular}{|l|r|r|r|r|r|}
\hline double $C_{1}+C_{e}$ & $\$ 7,000.00$ & $\$ 6,980.00$ & $\$ 6,900.00$ & $\$ 6,000.00$ & $\$ 5,000.00$ \\
\hline $2 \times$ Tech & $\$ 4,300.00$ & $\$ 4,280.00$ & $\$ 4,200.00$ & $\$ 3,300.00$ & $\$ 2,300.00$ \\
\hline
\end{tabular}

Let's consider the case without penalties. It is clear that, since any investment that goes into the rate base will raise revenues, all capital investments considered in Table 4 will raise the DP's profits compared to the base case. The DP is better off by spending more money to change the topology of the grid, than it is by investing in new technology. This also happens to coincidentally result in a better reliability level. The DP does not base its decision on the effects on reliability, however, but only seeks to maximize overall capital costs for its rate base. Increasing capital spending by investing in both Tech and Capital or doubling the amount of money spent on regular equipment or extra lines that do not have any influence on reliability level is also profitable (double $C_{1}+C_{e}$ ). The last row in Table 4 is also worth noticing: investing in smart equipment or in software that increases reliability is even more profitable if its cost is higher. In other words, there is no incentive for cost minimization in the purchasing process.

Another significant result is that penalties only begin to erode the DP's profit significantly if they are at least an order of magnitude larger than the price of energy. It is also worth noticing that $\mathrm{O} \& \mathrm{M}$ costs do not enter into the picture at all. In this sense, there is no incentive for investing in control technology to lower $\mathrm{O} \& \mathrm{M}$ costs or to spend more on maintenance to improve reliability, since neither assists the DP in maximizing profits.

Performance-based regulation overcomes some of the problems encountered by ROR regulation, such as the lack of incentives in cost minimization. In the next paragraph, we describe its main characteristics and provide a similar example in order to compare the results in terms of providing incentives for reliability and investment choices.

\section{Price-cap regulation with a penalty scheme for reliability}

Performance-based regulation (PBR) has various advantages over ROR: it delegates pricing to the firm within the limits imposed by the regulator, it is based on a profit motive, and it is compatible with competition. There are many different possible designs fir performance-based price regulation1. O ur example considers Price-Cap regulation (PC), snce it seems to have the desired properties for enhancing efficiency.

Price caps define an average price ceiling with weights $\mathrm{w}=\left(\mathrm{w}_{1}, \mathrm{w}_{2}, \ldots, \mathrm{w}_{\mathrm{n}}\right)$

$$
\sum_{\mathrm{k}=1}^{\mathrm{n}} \mathrm{w}_{\mathrm{k}} \mathrm{p}_{\mathrm{k}} \leq \overline{\mathrm{p}}
$$

not to be exceeded by the firm. The price ceiling is usually adjusted each year to account for inflation and expected technological progress. Within the price ceiling the firm is free to maximize its profits. That is, the price level is constrained, but not its cost structure (the firm is free to adjust its individual prices). The regulator fixes the ceiling prices for either all products or a basket of products (average or weighted price) and the firm is free to choose its prices at or below the ceiling. Like ROR regulation, PC fixes the firm's prices for some period of time, usually 4 or 5 years. Under PC regulation, the time between regulatory reviews is theoretically fixed, whereas under ROR it is up to the firm to file for a rate case when necessary.

\footnotetext{
${ }^{1}$ In addition to PC regulation other possible pricing scheme are yardstick regulation, profit sharing regulation, revenues caps, etc.
} 
As stated above, a positive aspect of PC regulation is price flexibility. Although the firm cannot affect the average price it charges, it can adjust its individual prices to reflect costs, elasticity of demand, complementarities and substitutability between segments, or competitive pressure. The structure of prices is therefore more consistent with economic efficiency and enables the firm to become more business oriented.

Moreover, the price caps are, in principle, not revised according to the firm's past performance. PC regulation is prospective rather than retrospective, in the sense that firm's historical costs are not meant to be the basis for future prices (PC regulatory reviews do not make explicit use of accounting data). As a result, prices caps are simpler to operate by the regulator and the company, and eliminate the link from cost inefficiencies to price increases and provide the firm with powerful incentives for cost reduction2.

In fact, price caps are less vulnerable to over-capitalization because the company has the right to keep whatever profits it can earn during the specified period (and must also absorb any losses). This provides an incentive for productive efficiency.

Regulatory adjustments to the price ceiling in the event of higher than expected profits for the DP redistribute the benefits efficiency gains to consumers, but may reduce the incentives for the DP to improve efficiency. Companies may believe that the short-term advantages of increased efficiency and lower costs will be offset by a lower price ceiling in the next period, and therefore will seek to make only incremental efficiency improvements, even when larger improvements are possible.

Moreover, the tendency of regulators to intervene when pressured to reduce prices or reduce a firm's losses creates uncertainties for the regulated firms and even more uncertainties for potential entrants in the market.

The incentives to reduce costs can create disincentive for quality. Because the firm can profit from reducing the costs of services, there is a tendency to reduce the quality of service. Price Cap regulation, therefore, should be accompanied by safeguards for quality (11], [7], [8]). This motivates the introduction of a penalty scheme for PBR similar to that in the ROR case.

In the second scenario examined in this paper, the DP is a regulated monopoly subject to PC regulation and offers both delivery and reliability service. Again, the two services are bundled into a single tariff paid by the grid users, and the utility pays penalties for failures to deliver power. The tariff $\overline{\mathrm{P}}$ is assumed to be equal to the ceiling price set by the regulator (again we consider here a linear tariff) and the penalties Pen) are assumed to be a given price per MWh for energy not delivered. Under this scheme the firm's objective function for a given season (2160 hours) is:

$$
\max \Pi=\mathrm{R}-\mathrm{C}=\overline{\mathrm{P}} \mathrm{Q}_{\text {tot }}-\mathrm{C}
$$

Under the assumption that the quantity demanded, $Q_{\text {tot }}$, is fixed for the season, the above profit maximization problem can be simplified as a cost minimization problem, as follows:

$$
\min _{\beta, K, P \text { en }, C_{0}} C=(\bar{P}+\rho) Q_{\text {un }}+C_{1}+C_{e}+C_{K}+C_{\beta}+(1-\alpha) C_{0}
$$

where:

$\mathrm{C}_{0} \quad$ is the cost of operations and maintenance

$\alpha \quad$ is a parameter that captures the effects of investing in capital or technology on $0 \& M$ costs

Using this objective function we ran a simulation on the same simple example grid, with the input data described below in Table 5 .

2 In principle PC are not determined by previous costs or rate of return, however it is clear that the firm's past performance is rationally used at $\mathrm{PC}$ reviews. 
Table 5 Basic input data for PBR (Priœ Caps) scenario

\begin{tabular}{|l|l|r|}
\hline Price (delivery only) (\$/MWh) & $\mathrm{P}_{\text {reg }}$ & 3.87 \\
\hline Time Period (hours) & $\mathrm{T}_{\text {tot }}$ & 2160 \\
\hline Average Demand $(\mathrm{MW})$ & $\mathrm{Q}_{\text {ave }}$ & 10 \\
\hline Outage penalty $(\$ / \mathrm{MWh})$ & $\mathrm{R}$ & 0.00 \\
\hline Cost of Equipment $(\$)$ & $\mathrm{C}_{\mathrm{e}}$ & $20,000.00$ \\
\hline Cost of Lines (\$) & $\mathrm{C}_{\mathrm{l}}$ & $15,000.00$ \\
\hline Cost of Operations (\$) & $\mathrm{C}_{\mathrm{o}}$ & $45,000.00$ \\
\hline Outages (/period) & $\mathrm{Int}$ & 1.00 \\
\hline Outage Duration (hours) & $\mathrm{D}_{\text {out }}$ & 2 \\
\hline Cost of Technology (\$) & $\mathrm{C}_{\mathrm{b}}$ & $5,000.00$ \\
\hline Cost of Capital Investment $(\$)$ & $\mathrm{C}_{\mathrm{k}}$ & $5,000.00$ \\
\hline
\end{tabular}

As in the ROR scenario, the average duration of outages varies accordingly to the investment choices. The numbers are given in Table 6 .

\section{Table $6 \quad$ E ffect of investments on Reliability}

\begin{tabular}{|l|c|r|}
\hline Outage with Nothing (hours) & Dout & 2 \\
\hline Outage with Tech (hours) & Dout $_{1}$ & 1 \\
\hline Outage with Capital (hours) & Dout $_{1}$ & 0.5 \\
\hline Outage with Tech and Capital (hours) & Dout $_{1}$ & 0.1 \\
\hline
\end{tabular}

In this case, the objective function contains the cost of operations and maintenance. An investment in certain technologies (such as monitors, AMR, and automatic switches) can significantly lower the cost of operations. A capital investment to change the topology of the grid will not reduce operational costs significantly and will slightly increase maintenance costs. Here we assumed that the overall effect was slightly lower $0 \& M$ costs. This effect has been modeled through the parameter $\alpha$, as in Table 7

Table 7 E ffect of investments on 0 peration Costs

\begin{tabular}{|l|c|r|}
\hline Effect on Operation Costs - Base Case & $\alpha$ & 0 \\
\hline Effect on Operation Costs - Technology & $\alpha$ & 0.1 \\
\hline Effect on Operation Costs - Capital & $\alpha$ & 0.05 \\
\hline Effect on Operation Costs - Both & $\alpha$ & 0.2 \\
\hline
\end{tabular}

The results of the simulation are given in Table 8. Solving the profit maximization problem stated in equation (4), the firm has a strong incentive to cut costs. Let's consider the first column in Table 8: profits drop considerably if the DP chooses the capital investment to change the topology of the grid. This happens even though the investment brings improvement to reliability and therefore reduces revenue losses due to $Q_{u n}$. For the technology investment, the DP's profits are reduced despite the resultant reductions in operational costs and the improvement in reliability. The overriding incentive for the DP is to reduce costs, and investment incentives are virtually eliminated. Introducing significant reliability penalties improves the previous situation, by providing incentives 
for investments aimed at improving reliability (when penalties are higher that 50). The level of these penalties, however, does not correspond to the costs of reliability or the consumers' values for reliability and therefore may increase inefficiencies.

Table $8 \quad$ PBR simulation results

\begin{tabular}{|l|r|r|r|r|}
\hline Penalties & \multicolumn{1}{|c|}{$\rho=0$} & \multicolumn{1}{c|}{$\rho=10$} & \multicolumn{1}{c|}{$\rho=50$} & \multicolumn{1}{c|}{$\rho=100$} \\
\hline Investment decision & \multicolumn{4}{|c|}{ Profit } \\
\hline Nothing (base case) & $\$ \mathbf{3 , 5 1 4 . 6 0}$ & $\$ 3,314.60$ & $\mathbf{\$ 2 , 5 1 4 . 6 0}$ & $\$ 1,514.60$ \\
\hline Tech & $\$ \mathbf{3 , 0 5 3 . 3 0}$ & $\$ 2,953.30$ & $\mathbf{\$ 2 , 5 5 3 . 3 0}$ & $\$ 2,053.30$ \\
\hline Capital & $\$ \mathbf{8 2 2 . 6 5}$ & $\$ 772.65$ & $\$ 572.65$ & $\$ 322.65$ \\
\hline Both & $\$ 2,588.13$ & $\$ 2,578.13$ & $\mathbf{\$ 2 , 5 3 8 . 1 3}$ & $\$ 2,488.13$ \\
\hline
\end{tabular}

Since the incentive to cut costs is significant, it is likely that the firm would attempt to reduce $0 \& M$ costs. This of course will lead to reductions in reliability, since maintenance of the lines and real time actions such as working overtime to complete repairs incur costs but are also extremely important to determining the reliability level. To illustrate the incentives to cut costs, we modeled the effects of a $50 \%$ reduction in O\&M expenditures. We assumed that as a consequence, the number of interruptions will rise to 10 per season and the average duration of the outages will become 10 hours per season. Nevertheless, if there are no penalties, the reduction in $0 \& M$ costs more than makes up for the losses from increased failure to deliver. The significant increase in the number of outages impacts profits only when the penalties become significant $(p>20)$.

Table 9 PBR simulation results with reduod (1/ 2) effort in $0 \& M$

\begin{tabular}{|l|r|r|r|r|}
\hline Penalties & \multicolumn{1}{|c|}{$\rho=0$} & \multicolumn{1}{c|}{$\rho=10$} & \multicolumn{1}{c|}{$\rho=20$} & \multicolumn{1}{c|}{$\rho=50$} \\
\hline Investment decision & \multicolumn{4}{|c|}{ Profit } \\
\hline Base Case & $\$ \mathbf{3 , 5 1 4 . 6 0}$ & $\$ 3,314.60$ & $\mathbf{\$ 3 , 1 1 4 . 6 0}$ & $\$ 2,514.60$ \\
\hline $1 / 2$ Effort & $\mathbf{\$ 2 2 , 2 2 2 . 0 0}$ & $\$ 12,222.00$ & $\mathbf{\$ 2 , 2 2 2 . 0 0}$ & $-\$ 27,778.00$ \\
\hline
\end{tabular}

Under PC regulation, the incentive to reduce costs is extremely high, and raises concerns about quality of service. There are no direct incentives to improve reliability (only to avoid penalties if those are significant). The motivation for investing in technology is driven solely by cost reduction considerations, and not by improvements in quality.

\subsection{Improvement on the above models: reliability insurance}

The regulatory schemes examined so far present some characteristics that are not satisfactory in terms of providing reliability or investing in upgrading the grid using smart technologies. Moreover the reliability provided is averaged on the grid, without any link to consumers' specific needs. We think that a regulatory mechanism that permits the consumers to reveal their preferences and that rewards the firm for its innovation and improvement on the grid is necessary. In fact, even if introducing a penalties schemes gives to the firm correct signals, on the other hand, only penalizes it case of an outage, it doesn't provide a reward for improving quality, and does not convey any information from the consumers (it is the regulator that sets the penalties). An improvement on the penalty scheme is an insurance type of scheme, as we are going to describe in the following paragraph. 


\section{Reliability insurance}

\subsection{Motivation}

The inherent weaknesses of regulatory schemes that utilize penalty functions for reliability service, as seen in the previous analysis, include a uniform reliability for all consumers with a single bundled tariff, the lack of efficient economic signals for investments in reliability, and the burden upon regulators to determine the value of service to the consumers. These can be overcome by a scheme which allows for consumers to choose a differentiated reliability service based upon their value for energy delivered (or alternatively their cost for energy not delivered). The introduction of insurance for reliability, purchased by the consumers from the D P provides an improved structure for efficient management of the grid.

This insurance provides that the DP reimburses the consumers for energy not delivered (outages) according to the consumers' value, which is determined by the insurance contract. The consumers pay an insurance premium for their selected coverage to the DP. This premium may be used to cover the costs of improving reliability or to pay reimbursements. Reliability insurance allows consumers to give the DP the proper signal of their value for reliability service and alleviates the risks that consumers currently are forced to accept. The risk is transferred to the DP, who as the owner and operator of the distribution grid is able to take actions to control reliability, in contrast to the consumers who are passive recipients of the reliability from the grid. The DP, in return for accepting the reliability risk, is able to profit from improvements in reliability.

The reasons for introducing reliability insurance on the distribution grid are numerous [3]. First, reliability insurance can be viewed as a form of product differentiation. Consumers willing to pay a higher price are given a higher priority in receiving the service. In other words, they receive a product with different characteristics in terms of quality. In fact, because consumers are free to choose among a menu of different insurance contracts offered by the DP, their selection reflects their value for the service. Consumers will choose a policy that correctly reflects their value for service. Therefore an allocation scheme under which D P serves consumers in order of their selected priority correctly reflects consumer preference.

Reliability insurance can be used to develop priority restoration schemes, maintenance (such as tree trimming) plans, and rationing schemes for curtailing excess demand in the event of a deficit on the supply side. In each case the DP makes decisions and assigns priorities according to the consumers' valuation of the service. Moreover, the same information can be used to guide longer-term investments in terms of capacity and technology upgrades to the grid.

The characteristics of the distribution grid allow for a pricing scheme that entails allocation of services according to consumers' valuation. Basing reliability insurance upon consumers' valuations creates efficient signals for investment and operational decision making by the DP. Recent advances and cost reductions in the technology of metering, control, and communication make the implementation of differentiated reliability feasible, and a regulatory scheme that includes reliability insurance will provide incentives for the DP to use them efficiently. Consumers on the other hand, are enabled to choose the reliability insurance according to their value for this service. This allows them to pay only for the level of reliability that they desire, while at the same time shifting the risk away from them to the DP. 
Reliability insurance should be combined with a performance based price scheme for the delivery service. This will allow for the unbundling of the delivery and reliability services. A cost of service based pricing scheme would necessitate the difficult if not impossible task of differentiating between costs for delivery and costs for reliability. Under a performance-based scheme, however, this is not necessary. The initial price cap should be set to allow the DP a reasonable return based upon the current delivery and reliability service. The reliability insurance will provide only for future changes in reliability. This eliminates the need for the regulator to differentiate between the costs of delivery and the costs of reliability. The future decisions of the DP will be based upon improving the efficiency in the operation and use of the grid.

\subsection{How it works}

In this paper, we investigate a regulatory scheme that includes reliability insurance based solely on the total amount of energy not served (total outage duration). Although frequency of outages and power quality are not considered here, the insurance scheme can be expanded to include each of these cases. The term outages is used to refer to the time duration of outages and does not consider frequency for the purposes of this paper.

Reliability insurance is based upon the current, easily measured, average reliability. The regulator establishes a standard offer for reliability insurance based upon the average reliability and an estimated value for service. The only determination that the regulator is required to make is the average value for service. This standard offer is designed such that if every customer chooses it and the DP maintains the status quo performance of the grid there is no change in either consumer's surplus or DP profitability. That is, the premiums charged for the standard insurance will be equal to the payouts as long as the standard level of reliability is maintained. The DP is free to offer insurance contracts for values above and below the standard offer. Consumers with higher or lower values for reliability service will cho ose the appropriate level of coverage. All consumers will initially receive the standard offer insurance and may select another coverage level if appropriate.

The reliability insurance contracts will require consumers to pay a premium, $P=f$ (rembursement, quantity, reliability), in advance (for example, at the beginning of a season) to obtain a subsequent (for example, at the end of the season) monetary reimbursement, $R=f(v a l u e$, reliability, quantity), for the total amount of energy that is not delivered [1]. Assuming risk neutrality, the consumers will choose a contract that provides for a reimbursement amount equal to their value for the service. We assume that revenues from the sales of reliability insurance are not used to meet DP revenue requirements for covering ordinary fixed and operational costs (this is recovered through the delivery tariff). In this case, the standard offer premium has the simple form $P=q \cdot R \cdot$ (ex pected outages) where $R$ represents the reimbursement rate [\$/MWh] for each unit of energy $q[\mathrm{MWh}]$ that is not delivered. The expected outages are determined by the average outages for the case of the standard offer.

Efficient pricing of reliability insurance is based on a simple principle: a customer who values the service provided by the DP, would require a reimbursement equal to his value, v. We can also interpret $\mathrm{v}$ as the loss experienced by that consumer because of the interruption. Given that $r$ represents the delivery reliability, then, for efficiency, the choice of the consumers will be the one that maximizes his benefit: $v \cdot r+v \cdot(1-r)-P(v, r)$.

In order to minimize the reimbursements payable in each contingency, the D P will prioritize delivery service for those customers with the highest values for the service since these will require the largest reimbursements. Consequently, the delivery reliability $r$ will be an increasing function of the reimbursement, or of the value of the service, for the consumer. Moreover, by way of the premium payment, reliability will be associated with the willingness to pay for it by the consumers and. The value and costs of reliability service is then unbundled from that of delivery service for both consumers and D Ps. 


\subsection{Contract Provisions}

In order to ensure that the DP is not bankrupted by reliability insurance provisions there are several terms that must be included in the contracts. First, the D P will not be responsible for outages in generation or transmission. (NOTE: the insurance could be expanded upward to transmission and generation either through the DP purchasing insurance from the transmission provider for the consumers or via ESPs or direct consumer purchase). This limits the risk that the DP faces to the distribution grid itself. Otherwise, poor management of the transmission grid or a lack of generation capacity could have severe implications on the reimbursements that the DP pays. Determining the source of outages to be distribution, transmission, or generation is generally straightforward.

The duration of insurance contracts must be such that they allow for the proper investment signals and the DP is not taken advantage of by consumers choosing initially high insurance values, only to change to a lower value after the DP has invested in equipment to ensure that the consumers reliability is improved. A good method to prevent this type of gaming of the system by consumers it to have a long duration for the insurance contracts with the ability to upgrade the coverage level at any time, but not to downgrade the coverage level arbitrarily. This will enable the DP to make investment decisions to upgrade the grid with reasonable certainty of the revenues from the insurance premiums.

Another concern for the DP is the case of catastrophic outages related to severe weather events such as a hurricane. Although the D P obviously does not have direct control over such events, it is able to take precautions against such events through investments such as moving lines underground. Using the revealed values for the service shown by the insurance coverages selected by its consumers, a D P can determine whether or not such investments are economically efficient. At the same time, a may D P may take out an insurance policy with a large insurance company to prevent such an event from bankrupting the D P's reliability fund.

\subsection{Example}

The following simple example illustrates that overall social welfare is improved using reliability insurance to express the value of reliability service. Consumers are offered a menu of three choices for insurance and it is compulsory that they buy one of them. A standard contract (S) that is associated with the current level of reliability and is instituted by the regulator, a higher than standard reliability contract $(\mathrm{H})$ and a lower than standard $(\mathrm{L})$. Consumers will choose an appropriate insurance contract according to their valuation of service and will receive a reimbursement equal to their expressed value in case of failure to deliver by the DP. The insurance scheme requires that the standard contract (premium, value and reliability level) be set by the regulator in order to avoid overcharges by the D P. Since the consumers consequently self select their insurance contract from a menu of choices, it does not really matter that the regulator capture exactly the consumer needs for this particular contract. Its function is to set a benchmark around which the DP will set its charges and to make sure that the benchmark premium is reasonable in price.

For example, in Table 10 below we report a possible menu of choices (numbers are chosen only to serve as an example). Note that in the table, Value, $\mathrm{v}=$ Reimbursement for outages, and $\mathrm{r}=$ expected average reliability of the customers choosing each policy 
Table 10 Menu of dhoims

\begin{tabular}{|l|c|c|c|}
\hline Insurance & $\begin{array}{c}\text { Premium - P } \\
(\$ / \mathrm{MWh})\end{array}$ & $\begin{array}{c}\text { Value }-V \\
(\$ / \mathrm{MWh})\end{array}$ & $\begin{array}{c}\text { Rel Level }-r \\
\left(\mathrm{~h} / \mathrm{TS}_{\mathrm{S}}\right)\end{array}$ \\
\hline High & 0.48 & 500 & $99.95 \%$ \\
\hline Standard & 0.2 & 200 & $99.90 \%$ \\
\hline Low & 0.08 & 100 & $99.80 \%$ \\
\hline
\end{tabular}

The scheme provides an increase in welfare for both the consumers and the D Ps. Let's examine the consumer benefit first and then the DP benefit

From the consumers' point of view the net benefit with no insurance is given by:

$\mathrm{CB}=\mathrm{V} \cdot \mathrm{r} \quad$ consumer benefit without insurance

$\mathrm{CB}=\mathrm{v} \cdot \mathrm{r}-\mathrm{P}+(1-\mathrm{r}) \cdot \mathrm{v} \quad$ consumer benefit with insurance

0 summarizes the results of the consumer benefit calculation for each case.

For consumers who buy the standard contract, their overall welfare does not change with or without insurance. The consumer will simply see the differential cost of reliability unbundled from the cost of delivery. (Note: this will be the differential cost of reliability since the current standard reliability costs are still bundled in the delivery charge - it would be quite difficult, if not impossible to separate the two costs for the current state of the grid.) On the other hand, consumers with higher or lower values for reliability will be better off by choosing the contract that best reflects their value of service. Consumers who value reliability more will be better off buying the high insurance contract (benefit is with insurance $499.52 \$$ and 499.50 without it). The consumer who has a lower value for service than the standard will be again better off with insurance: his benefit will go from $99.90 \$$ without insurance to $99.92 \$$ with it.

Table 11 Consumer Benefit

\begin{tabular}{|l|c|l|c|l|c|}
\hline \multicolumn{1}{|c|}{ High } & CB $(\$)$ & \multicolumn{1}{|c|}{ Standard } & CB $(\$)$ & Low & CB $(\$)$ \\
\hline Insur H & 499.52 & Insur H & 199.67 & Insur H & 99.72 \\
\hline Insur S & 499.50 & Insur S & 199.80 & Insur S & 99.90 \\
\hline Insur L & 499.12 & Insur L & 199.72 & Insur L & 99.92 \\
\hline No Insur & 499.50 & No Insur & 199.80 & No Insur & 99.90 \\
\hline
\end{tabular}

The insurance scheme is designed so that the consumer self-selection results in buyers maximizing their benefit by choosing the contract that truly corresponds to their value of service. For example, the consumer whose value for service is $\$ 500 / \mathrm{MWh}$ will buy the High Insurance coverage in order to maximize their benefits (499.52\$). There is no incentive to choose a lower coverage, since it will not fully reimburse them for losses in case of outages. In the same manner, consumers that value service at $\$ 200$ / MWh will be better off with a lower level of coverage. 0 shows that their benefit is maximized (99.92\$) for the case where they choose exactly the level of service that corresponds to their value for service. 
As long as premiums are less than or equal to the expected benefit from reimbursements, the consumers will benefit from choosing the insurance that corresponds to their value. If the DP does not offer coverage for the consumer's value at a low enough premium level then the consumer can choose the standard offer insurance and will not be any worse off than without insurance. In addition, the consumer will be able to compare the costs of the higher insurance to outside sources of reliability insurance, such as contracting with distributed generation, backup generators, etc and in this way limited competition for the reliability service can be introduced.

A D P, for example might be able to contract for backup generation for two or more very high value customers located near one another at a lower cost than any one of the customers would be able to purchase an individual backup generator. In this case, the DP could offer the insurance for these very high value customers at a premium lower than the price the customers currently pay for their own backup generators. Currently, customers do not have this option of contracting with D Ps for differentiated reliability and must develop their own methods for insuring reliability when they have a higher value than the standard reliability offers.

From the DP point of view, the introduction of reliability insurance offers the opportunity to increase profits and provides efficient price signals for operations and investment decisions. In the case where the DP offers only the standard insurance, there is no change in the profit of the DP (or the consumer surplus). The DP will only offer other levels of insurance at a premium that provides for the costs of providing the differential reliability associated with that contract. In this case, the difference between the costs of providing differential reliability to the consumers and the revenues collected from premiums is positive.

The D Ps' profit formulation is:

Profit $=$ Premiums $(\mathrm{P})$ - Costs of Differential Reliability $(\mathrm{C})$ - Reimbursements (r)

$$
\Pi=\sum \mathrm{P}_{r h}+\sum \mathrm{P}_{r s}+\sum \mathrm{P}_{r l}-\left(\sum \mathrm{C}_{r h}+\sum C_{r s}+\sum \mathrm{C}_{r l}\right)-\left(\sum \mathrm{r}_{r h}+\sum r_{r s}+\sum \mathrm{r}_{r l}\right)
$$

Under the assumption that providing the current level of reliability does not require the DP to incur any additional costs, in the case of the Standard insurance scheme the difference between the premiums collected and the expected reimbursements paid is zero:

$$
\Pi=(0.2 \$ / h)-(200 \$ / h)(1-0.999)=0 .
$$

For the other two cases in the example in Table 11, in order for the DP to break even, the costs of providing differential reliability can be computed as follows:

- High reliability case:

$$
\Pi=0 \Leftrightarrow \text { premium }-(\$ 500 / \mathrm{MW} \mathrm{h})(1-0.999)=0 \Rightarrow \text { premium }=\$ 0.23 / \mathrm{MW} \mathrm{h}
$$

- Low reliability case:

$$
\Pi=0 \Leftrightarrow \text { premium }-(\$ 100 / \mathrm{MWh})(1-0.990)=0 \Rightarrow \text { premium }=\$-0.12 / \mathrm{MWh}
$$

In the low reliability case, we obtain a negative result: this indicates, in reality, the savings from allowing for reduced reliability for those customers for whom the standard level is too high for their value of service.

In the example, the DP will make a profit as long as it is able, on average, to provide the expected levels of reliability for less than the net costs indicated above. In this case, the DP must be able to 
increase the reliability of the high value customers from $99.90 \%$ to $99.95 \%$ at a cost of less than $\$ 0.23$ / MWh. It also must be able to save $\$ 0.12 /$ MWh by allowing for a reduction from $99.90 \%$ to $99.85 \%$ for customers with low value for service. The DP can profit from efficient investments in providing differentiated reliability to consumers according to the consumer's values for the service.

Therefore the DP, which knows the costs for providing differentiated reliability, will set premiums as follows:

Premium $_{\mathrm{i}}=\mathrm{V}_{\mathrm{i}}\left(1-\mathrm{r}_{\mathrm{i}}\right)+\mathrm{C}_{\mathrm{ri}} \quad \mathrm{i}=\{\mathrm{H}, \mathrm{L}, \ldots\}$

where $r_{i}$ is the expected reliability associated with each contract.

As stated before, it is necessary for the regulator to set the Standard insurance offer, i.e. the average value of service and the expected level of reliability. Since the regulator does not have perfect information about the D P's costs for reliability, he will set the reliability level at the current average level, and will estimate the average value. The resultant premium will be:

Premium $_{\mathrm{S}}=\mathrm{v}_{\mathrm{S}}\left(1-\mathrm{r}_{\mathrm{S}}\right) ; \mathrm{r}_{\mathrm{S}}=$ arrent average reliability

The regulator should be able to make a sufficiently accurate estimate of the average value for service. This value does not need to be perfectly determined, however, since the choices made by consumers in purchasing the different contracts will adjust the market. The consumers' preferences will reveal the correct value of reliability on the distribution grid. Overall, both consumers and the DP may benefit from the implementation of reliability insurance.

\subsection{Implementation}

From the DP perspective, the transition to implementing reliability insurance from the current methods of managing the grid requires making investment decisions based upon the new profit maximization function. The following example shows that the DP will have incentives for maintaining reliability and investing in efficient reliability improvements based upon the consumers value (in addition to the cost minimization incentives provided by the PBR).

Using the same example grid as in the previous cases, the DP will determine the levels of reliability to provide for each customer based on the costs of reliability and the reimbursement payments.

Given the three choices for insurance shown above, two of the four loads choose the standard value of insurance, one chooses high, and the last chooses low.

Table 12 Choios for insurance

\begin{tabular}{|c|c|c|c|c|}
\hline & $\begin{array}{c}\text { Premium } \\
(\$ / M W h)\end{array}$ & $\begin{array}{l}\text { Penalty } \\
\text { (\$/MWh) }\end{array}$ & $\begin{array}{l}\text { Number of } \\
\text { Customer }\end{array}$ & $\begin{array}{l}\text { Premium } \\
\text { Collected }\end{array}$ \\
\hline Standard & 0.2 & 200 & 2 & $\$ 2,160.00$ \\
\hline High 1 & 0.48 & 500 & 1 & $\$ 2,592.00$ \\
\hline Low 1 & 0.08 & 100 & 1 & $\$ 432.00$ \\
\hline
\end{tabular}

The DP then makes the decision (via investments, maintenance, restoration schemes, etc) as to what expected reliability to offer each customer group. We examined the following four options and their affect on the profits of the DP:

Table 13 Insurance options 


\begin{tabular}{|l|r|r|r|r|}
\hline Options: & \multicolumn{1}{|l|}{ Rel1 } & \multicolumn{1}{l|}{ Rel2 } & \multicolumn{1}{l|}{ Rel3 } & \multicolumn{1}{l|}{ Rel4 } \\
\hline High Customers & $99.90 \%$ & $99.95 \%$ & $99.85 \%$ & $99.95 \%$ \\
\hline Standard Customers & $99.90 \%$ & $99.95 \%$ & $99.85 \%$ & $99.90 \%$ \\
\hline Low Customers & $99.90 \%$ & $99.95 \%$ & $99.85 \%$ & $99.85 \%$ \\
\hline
\end{tabular}

Calculating the effects of each option on the DP's expected profits compared to the expected DP profits without the insurance scheme illustrates the affects on DP decisions. First, the expected profits for each reliability option are calculated assuming no changes in cost to the D P (Row 2). This result is then compared to the expected profit with no insurance scheme (Row 1) to determine what the breakeven cost of offering each option would be for the D P (Row 3).

Table $14 \quad$ Ex pected profits

\begin{tabular}{|l|r|r|r|r|}
\hline Decisions: & \multicolumn{1}{|c|}{ Rel1 } & \multicolumn{1}{|c|}{ Rel2 } & \multicolumn{1}{|c|}{ Rel3 } & \multicolumn{1}{c|}{ Rel4 } \\
\hline No Insurance & $\$ 3,508.41$ & $\mathrm{~N} / \mathrm{A}$ & $\mathrm{N} / \mathrm{A}$ & $\mathrm{N} / \mathrm{A}$ \\
\hline Insurance & $\$ 3,292.41$ & $\$ 6,034.20$ & $\$ 550.61$ & $\$ 4,112.86$ \\
\hline Breakeven $C_{\text {rel }}$ & $-\$ 216.00$ & $\$ 2,525.80$ & $-\$ 2,957.80$ & $\$ 604.45$ \\
\hline
\end{tabular}

This table shows that the DP will lose money (compared to the base, no insurance case) if it does nothing (Rel1). If the DP is able to maintain the standard reliability for all customers while reducing costs by more than $\$ 216$, however, the DP will increase its profits. The DP has a strong incentive not to allow the standard reliability to fall below the standard level. The third option (Rel3) shows that the DP must be able to save almost \$3000 from cost cutting measures that would result in only a $0.05 \%$ reduction in the reliability for all the consumers. (As previously discussed, once the consumers have purchased insurance coverage equal to their value for reliability, they are indifferent between receiving service and receiving a reimbursement. Thus, the consumers are indifferent to the actual reliability level they receive.) Examining the option of a uniform increase in reliability for all consumers (Rel2), the DP will find that if they are able to do so for less than $\$ 2,525.80$, their expected profit will be greater than in the base case. The final option (Rel4), is the case where the D P provides each customer exactly the reliability associated with their insurance contract. In this case, the combination of the costs for improving the reliability of one customer minus the savings associated with reducing the reliability of another must be less than $\$ 604.45$ for the DP to increase profits. This differentiation may be accomplished by measures as simple as assigning priority to restoration to the high value customer or increasing tree trimming on the lines serving the high value customer.

The DP will evaluate the costs of offering the differentiated reliability and compare this to the expected profits resulting from various options to determine the most efficient operation and investments in the grid. These investments will be determined according $b$ the consumers' now transparent values for the reliability service.

\subsection{Consumer aggregation}

To efficiently manage the grid with reliability insurance, a DP will be able to utilize consumer aggregation for making decisions at all levels of the grid. The example of the four loads system can be generalized to any four areas of the grid that are physically separable, and are not limited to differentiation at the lowest consumer level. This will enable the DP to make economically efficient investment and operations decisions, including technological upgrades and the development of restoration schemes, and maintenance and operations plans to maximize profit according to consumer preference. 
At the beginning of a season, the DP be able determine the values of reliability at each level of aggregation of the grid according to the insurance contracts that the consumers have chosen. The D P will then be able to develop maintenance, restoration, and other operational plans to minimize the reimbursement payments it will have to pay. Depending upon the availability of technology and the topology of the grid, the DP may choose to invest in modifications to the grid to allow for a higher level of reliability for those customers with a higher level of insurance coverage. D epending on the status of controls and communications available on the grid, the DP will be able to differentiate reliability according to consumers' preferences all the way down to the household level or at a more aggregate level. For example, distinguishing a residential area from an industrial area, or residential and industrial areas with different values for service. Moreover, we should consider that a distribution grid is mainly radial, but becomes looped in urban areas. The two topologies present different characteristics in terms of restoration and curtailment schemes as well as protection schemes, and therefore different opportunities to implement differential reliability

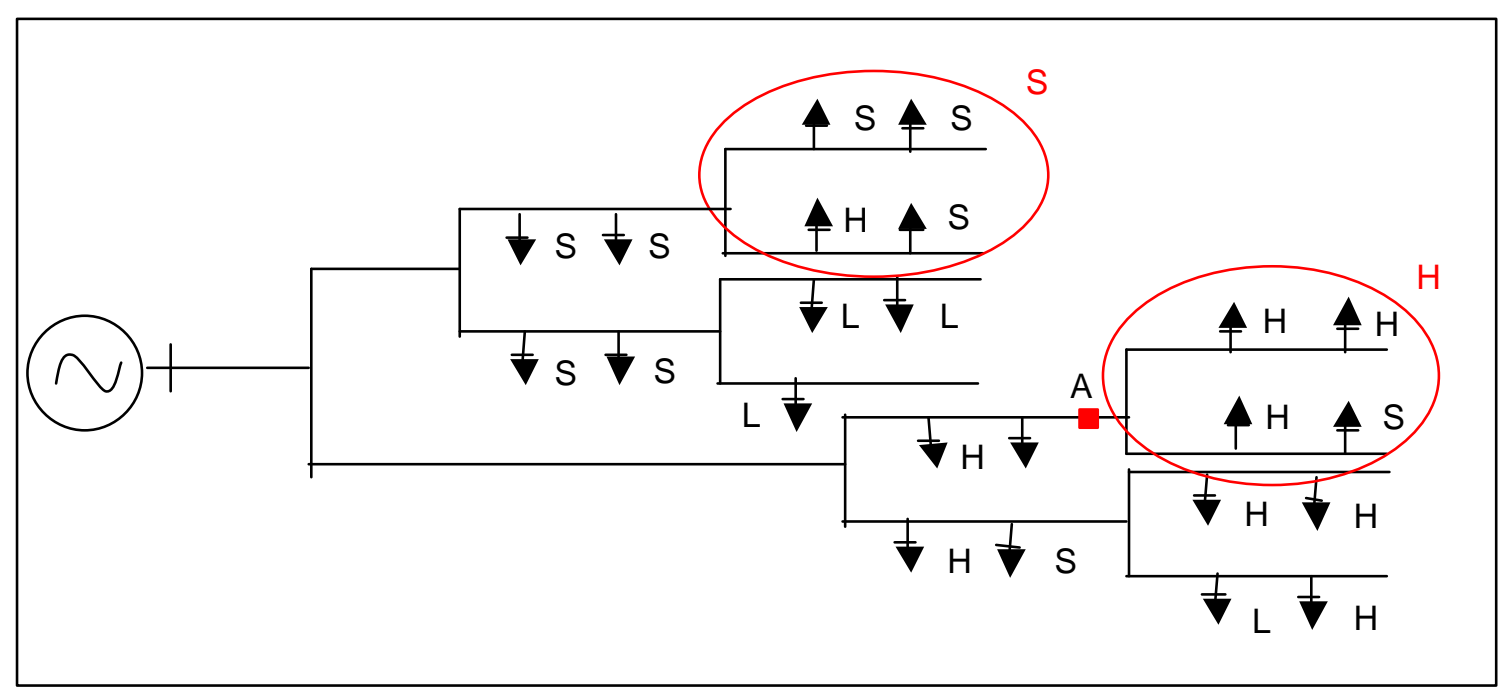

Figure 2 Consumer aggregation on a radial distribution grid

Let's consider, for example, a radial distribution grid, as depicted in Figure 2. If the available technology allows the DP to provide a differentiated reliability level at each consumer site (using for example AMR at each load) consumers will receive their contracted level of reliability. If the available technology permits the D P to provide differentiated reliability at the feeder level for a lower cost (by placing, for example, a smart switch or automatic recloser at point A), consumers will be grouped according to the average level of reliability requested at the feeder level (in this case High). In other words, the DP will simply calculate the sum of the reimbursement levels for every customer on each branch at the feeder, and provide a higher level of reliability to the branch that demands higher reimbursements. Consumer aggregation will be done in such a manner so to accommodate consumer preferences, given the technology constraints. The DP will maximize its profits by providing the service that consumers request.

The D P objective function under this scheme is as follows:

$$
\max \Pi=R-C=\bar{P} Q_{t o t}+\sum_{i} \text { Prem }_{\mathrm{i}} \cdot \text { Customer }_{i}-C-\sum_{i} \text { Pen }_{i} \quad \mathrm{i}=\mathrm{S}, \mathrm{L}, \mathrm{H}
$$

where:

$\mathrm{R} \quad$ is revenues; 
C is total costs (fixed and variable);

$\overline{\mathrm{P}} \quad$ is the electricity price per $\mathrm{kWh}$, under price cap regulation;

$Q_{\text {tot }}$ is the total amount of energy transferred by D P during that season;

$P e n_{i} \quad$ is the total reimbursement payments for all outages

Reliability insurance reveals consumers' values for service and ensures these values are taken into account in managing flows on the distribution grid. It allows the consumers who desire a higher reliability to pay for this service, without mandating this service is universally implemented at a single charge for all customers. This frees customers with a lower value for reliability from having to share the costs of a higher level of reliability.

\section{Conclusions}

Implementing reliability insurance on the distribution grid provides a regulatory enhancement to performance-based regulations with penalties. It provides incentives for the optimal use of the grid according to consumers' values of service. Since the choice of coverage level reveals the consum ers' values for service, DPs will be given the proper incentives for efficient investment and management of the distribution grid. The risk associated with outages will be shifted from consumers who have no ability to control the outages to the DP, which is able to influence reliability through its investment and operational decisions.

The insurance scheme also allows for the unbundling of the delivery and reliability services and will allow consumers to compare the costs of other methods of improving reliability such as purchasing backup generation. The differential reliability service that would result from implementing insurance will allow consumers to pay only for the level of reliability that is most appropriate for them, no more and no less.

\section{0 pen questions}

Since the consumers consequently self select their insurance contract from a menu of choices, it does not really matter that the regulator capture exactly the consumer needs for this particular contract.

Gaming - what if customers choose another level??? - accepting risk -= will know that they are accepting risk

How the DP chooses to offer other levels of insurance -

Eq.

Intertemporal differentiation of coverage and differentiated coverage for portions of a consumers demand

\section{Further research}

Further research is required in evaluating the validity of the results in a dynamic sense. The validity of signals that come from the insurance scheme need to be measured against a repeated period of insurance contracts purchase by consumers: this will permit to assess the DP strategy, both on investment and in the use of technology for communication and control, and to evaluate the improvement in the social welfare in the long run.

Investigation is required in order to determine whether the insurance scheme can be used also to enhance the provision of power quality, not only continuity of service, as it was done in this paper. 
The concept of power quality extents to frequency of outages, momentary interruptions, and voltage sags. The provision of those services was not addressed in this paper.

Finally the overall paradigm of the market structure and of the utility structure changes in presence of distributed generation. Since penetration of DG is already observable, it would be interesting to capture the inherent transformations it brings in the consumers' and in the DP's behavior, under different regulatory structure.

\section{References}

[1] Averch H., Johnson L.L., 'Behavior of the firm under regulatory constraint' A merican E conomic Review, Vol. 52, 1962.

[2] Beesley M., Littlechild S., 'The regulation of privatized monopolies in the United Kingdom', RA N D Journal of E conomics, Vol. 20, No.3, Autumn 1989.

[3] Chao H., Peck S., 'An institutional design for an electricity contract market with central dispatch', The E nergy Journal, Vol.18 No.1, 1997.

[4] Chao H., Wilson R., 'Priority service: pricing, investment, and market organization', The A merican E conomic Review, Vol. 77, No 5, D ecember 1987.

[5] Crew M., Kleindorfer P., 'Incentive regulation in the United Kingdom and the United States: some lessons', Journal of regulatory economics, Vol. 9 and 10, 1990.

[6] Deng S., O ren S., 'Priority network access pricing for electric power', Power W orking Paper, PWP072, February 2000.

[7] Laffont J-J., Tirole J., A theory of incentives in procurement and regulation, The MIT Press, 1993.

[8] Laffont J-J., Tirole J., Competition in telecommunication, The MIT Press, 2000.

[9] Manove M., 'Provider insurance', The Bell Journal of E conomics, Vol. 14, Autumn 1983.

[10] Wilson, R., 'Implementation of priority insurance in power exchange markets', The E nergy Journal, Vol.18 No.1, 1997.

\section{Acknowledgments}

The authors would like to thanks Prof. Ingo Vogelsang for insightful comments and discussions. They would like also to acknowledge Anuradha Saxena for her participation the development of the penalty scheme, earlier in the project.

The authors greatly appreciate the financial support by the MIT Energy Lab and ABB Corporation Project D istributed Power Industry of the F uture (MIT G rant \#6866200), and the doctoral fellowship from the Italian 'Ministry of University and Scientific and Technological Research'. 